\title{
Characterization of surfaces obtained by micro-EDM milling on steel and ceramic components
}

\author{
G. D’Urso ${ }^{1}$, C. Giardini², M. Quarto ${ }^{3}$ \\ ${ }^{1}$ University of Bergamo - DIGIP - Viale Marconi 5, 24044 Dalmine (BG) - Italy - gianluca.d-urso@ unibg.it \\ ${ }^{2}$ University of Bergamo - DIGIP - Viale Marconi 5, 24044 Dalmine (BG) - Italy - claudio.giardini@ unibg.it \\ ${ }^{3}$ University of Bergamo - DIGIP - Viale Marconi 5, 24044 Dalmine (BG) - Italy - mariangela.quarto@ unibg.it
}

Keywords: micro-EDM milling, surface finishing, ISO 25178, AISI 316L, ZrC+10MoSi 2

\begin{abstract}
This work deals with the execution of micro-pockets on two different materials (AISI 316L stainless steel and $\mathrm{ZrC}+10 \mathrm{MoSi}_{2} \mathrm{UHT}$ ceramic) using micro-EDM milling. The experiments were carried out by varying process parameters supposed to influence the surface quality, namely: discharge pulse on time, peak current, voltage and frequency. For both materials, tungsten carbide cylindrical electrodes were used. The investigation focused on the different results obtained in terms of surface roughness $\left(S_{\mathrm{a}}\right)$, kurtosis $\left(\mathrm{S}_{\mathrm{ku}}\right)$ and skewness $\left(\mathrm{S}_{\mathrm{sk}}\right)$ to evaluate the different finishing level of the surface obtained as function of the process parameters. The aim of the present paper is to propose a method for studying the surface characteristics in terms of peaks and valleys shape and distribution with respect to the mean line according to ISO 25178. The results of this analysis can provide important information when designing micro-EDM milling processes.
\end{abstract}

\section{Introduction}

During the last years, the need of micro-elements quickly increased in various application areas such as medical, automotive, microelectronic and telecommunication. In particular, this process has found several applications in mould and die manufacturing, small and burr-free hole drilling. Many existing technologies were downscaled and new innovating manufacturing processes were 
developed to produce parts characterised by feature size smaller than few micrometres [1]. As well as the traditional machining as turning and milling, non-conventional operations are also being contemplated; in particular, electrical discharge machining (EDM) provides various possibilities for achieving complex shapes with high characteristics on conductive materials regardless of their hardness and strength [2]. EDM is a non-conventional technology based on electrical discharges generated in the gap between the electrode and the workpiece. Since there is no direct contact between tool and workpiece, cutting forces and mechanical stress are not produced and it allows to machine components with high precision and without any risk of tool breakage $[3,4]$.

Furthermore, it is a competitive method for ceramic parts processing because of the abilities to provide accurate, cost-effective and flexible products. Even though several processes are available for machining these hard to cut materials (abrasive jet, abrasive waterjet, ultrasonic machining, chemical and electro-chemical machining), EDM can be very effective and advantageous for complex 3D shapes [5].

The sparks generated during the machining produce heat that melts and vaporises the workpiece material while the dielectric medium removes the melted material from the surface. Despite finishing micro-EDM operations can produce precise parts, the roughing micro-EDM phases generate surfaces with low characteristics in terms of surface roughness. This can be due to the melted material that is incompletely flushed away while the remaining material re-solidifies and produces craters, micro-cracks and pores. These imperfections, caused by high temperature, may reduce the precision and the operating life of the machined components [6]. The recast structure is typically very fine rained, hard and may be alloyed with carbon from the cracked dielectric or with material transferred from the tool [7].

For these reasons, the surface finishing is one of the most important issues investigated and it is influenced by the process parameters, the material properties (workpiece and electrode) and the type of dielectric $[4,5]$. The surface quality has been recognized as an important requirement in many application fields and it is specified as a component requirement for many produced parts, in order 
to satisfy desired functionality [8]. In many engineering applications, maintaining some amount of surface roughness is very important to have adequate contact between components, hence surface roughness controls are mandatory to define the process, to validate the quality of the machined parts [9] and it has been found useful in machine tool monitoring [10].

All surfaces have a form of texture depending on peaks and valleys. These peaks and valleys vary in height and spacing and have properties related to the producing strategy. Roughness parameters can be calculated with either $2 \mathrm{D}$ or $3 \mathrm{D}$ measures. In many cases, a single parameter $\left(\mathrm{R}_{\mathrm{a}}\right.$ or $\left.\mathrm{S}_{\mathrm{a}}\right)$ could not be enough for the surface full description $[10,11]$. Therefore, many parameters and methods were developed over the years to enable improved ways of surface description [11-15]. Despite of the large investigation about surface roughness parameters, the arithmetical mean height of the scale limited surface $\left(\mathrm{S}_{\mathrm{a}}\right)$ is the most used parameter, because it is easy to evaluate and well established $[11,16]$.

Surface roughness is usually categorized into three groups according to its functionality. These groups are defined as amplitude parameters, spacing parameters and hybrid parameters. Amplitude parameters are the most important for the surface topography characterization. They are used to measure the vertical characteristics of the surface deviations. Among them, the most relevant 3D are: arithmetic average height $\left(\mathrm{S}_{\mathrm{a}}\right)$, root mean square roughness $\left(\mathrm{S}_{\mathrm{q}}\right)$, skewness $\left(\mathrm{S}_{\mathrm{sk}}\right)$ and kurtosis $\left(\mathrm{S}_{\mathrm{ku}}\right)$. The spacing parameters are those which measure the horizontal characteristics of the surface deviations, such as high spot count (HSC), peak count $\left(\mathrm{P}_{\mathrm{c}}\right)$ and so on. This group of parameters is very important for obtaining consistent lubrication. Bounding and more uniform finishing are possible by controlling the spacing parameters. The hybrid parameters are a combination of amplitude and spacing parameters. Any changes occurring in either amplitude or spacing may have effects on the hybrid property. In tribology analysis, surface slope, surface curvature and developed interfacial area are considered to be important factors, too [17- 19]. During the last years, many researchers try to analysis the surface topography developed different methodology. For example, J.M. Hyde et al (2014) demonstrates the utility of scanning laser 
confocal microscopy to measure the topographies of surfaces machined by micro-EDM. The measurements can be used to characterize these in order to demonstrate high confidence in the ability to discriminate as well as producing strong correlations with the discharge energies used to create the surfaces [20]. Z. Xiaoliang et al (2017) showed that the surface quality of EDM is deteriorated with the increment of the pulse current and pulse on time, in fact, the surface roughness of the machined surface increases by increasing the pulse current and pulse on time [21]. W. Feng et al (2017) conducted a systematic research on the surface morphologies of three high-performance alloys machined by micro-EDM and described a novel surface evaluation method combining fractal theory and wavelet filter [22].

The aim of this work is the identification of the surface characteristics of micro-pockets executed on two different materials (AISI 316L stainless steel and $\mathrm{ZrC}+10 \mathrm{MoSi}_{2}$ UHT ceramic) using microEDM milling. The experiments were carried out by varying process parameters and using, for both materials, tungsten carbide cylindrical electrodes. The investigation focused on the different results obtained in terms of surface roughness $\left(\mathrm{S}_{\mathrm{a}}\right)$, kurtosis $\left(\mathrm{S}_{\mathrm{ku}}\right)$ and skewness $\left(\mathrm{S}_{\mathrm{sk}}\right)$. These results provide important information when micro-EDM milling processes are designed. The analysis was carried out using a method based on the surface sampling and on the processing of the obtained points cloud.

\section{Experimental set-up}

Experimental tests based on the execution of simple micro-slots (Fig. 1) were carried out using micro-EDM machine Sarix SX-200. The micro-slot was design by a CAD software and then by a CAM it is defined the electrode for the machining.

Two different types of workpiece materials were taken into account: stainless steel plates (AISI 316L) and ultra-high temperature ceramic (UHTC) material $\left(\mathrm{ZrC}+10 \mathrm{MoSi}_{2}\right)$. The experimental campaign was carried out varying several process parameters, namely pulse-on-time $\left(\mathrm{T}_{\text {on }}\right)$, peak current $(\mathrm{I})$, voltage $(\mathrm{V})$ and frequency $(\mathrm{F})$ reported in Table 1. It is important to remark that peak current is only and index established by machine builder. These parameters are strictly related to the 
different machining types: pre-roughing, roughing, finishing and fine-finishing. The machining type identify the different finishing level of the machined surface and consequently it indicates the pulse type used during the process. In particular, for very precise finishes (finishing and fine-finishing), it will be necessary to use short and very short pulses. If you want fast removal (pre-roughing and roughing), it will be necessary to use high power pulses. Tungsten carbide cylindrical electrode, having a diameter equal to $0.3 \mathrm{~mm}$, was used. Hydrocarbon oil was used as dielectric fluid.

Preliminary tests were performed for the identification of the optimal process parameters, starting from electrode characteristics (material and geometry), workpiece material and machining type, in particular to optimize the electrode wear compensation.

Table 1. Main process parameters.

\begin{tabular}{l|cccc} 
Machining Type & $\begin{array}{c}\text { Pulse on } \\
\text { time } \\
{[\boldsymbol{\mu s}]}\end{array}$ & $\begin{array}{c}\text { Frequenc } \\
\mathbf{y}[\mathbf{k H z}]\end{array}$ & $\begin{array}{c}\text { Peak } \\
\text { Current } \\
{[\text { index] }}\end{array}$ & $\begin{array}{c}\text { Voltage } \\
{[\mathbf{V}]}\end{array}$ \\
\hline Pre-Roughing & 6.6 & 90 & 80 & 150 \\
Roughing & 5 & 130 & 50 & 130 \\
Finishing & 5 & 140 & 100 & 100 \\
Fine-Finishing & 2 & 180 & 100 & 90 \\
\hline
\end{tabular}

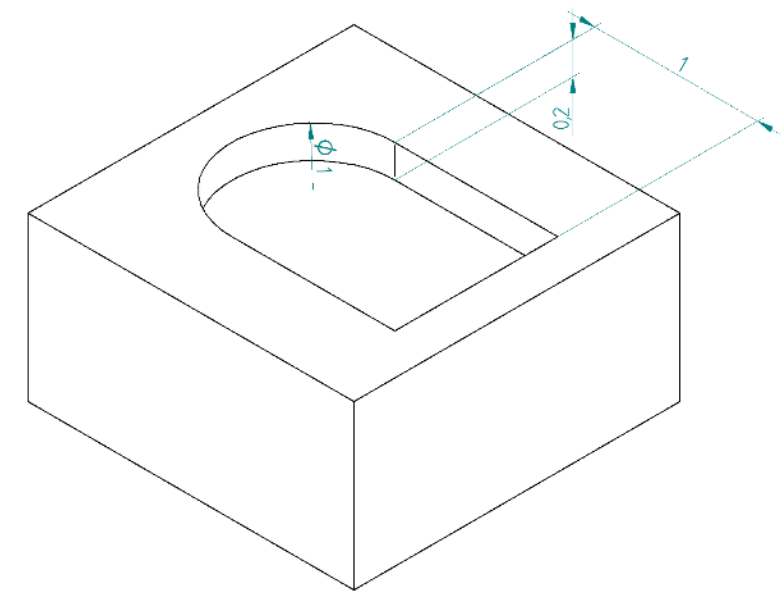

Fig. 1. Details of the micro slot. 


\section{Criteria for the evaluation of the machined surfaces}

\subsection{D reconstruction}

A 3D reconstruction of the micro-slots was performed by means of an autofocus laser probe equipment Mitaka PF-60. The physical principle of measurement is the autofocus variation along $\mathrm{Z}$ axis with a resolution of $1 \mathrm{~nm}$. The autofocus microscope measures height in $\mathrm{Z}$ axis and the $\mathrm{XY}$ stage moves the sample in order to obtain XYZ coordinate values for $2 \mathrm{D}$ and 3D measurements. A portion of the entire pocket surface, equal to a square area (A) of $0.5 \times 0.5 \mathrm{~mm}$, was taken into account. Fig. 2 shows the part of the pocket scanned. Table 2 shows the acquisition parameters. After the scansion of the area, the raw data were extracted and elaborated with a software developed by the authors. This software is able to level the surface eliminating the form factor (waviness), to reconstruct the surface by means of a tassellation algorithm, to save this surface in STL format for successive analysis in GOM environment and to calculate the amplitude parameters.

After the surface reconstruction, the GOM Inspect (a free 3D inspection and mesh processing software for dimensional analysis of 3D point clouds) is used to study the deviation of meshes with respect to a reference plane. The results of the computation are displayed in colours as function of the distance of each surface point from the reference plane.

Table 2. Acquisition parameters used for surface scanning.

\begin{tabular}{c|c}
\hline Acquisition Parameters & Values \\
\hline X Resolution & $0.6 \mu \mathrm{m}$ \\
Y Resolution & $0.6 \mu \mathrm{m}$ \\
Z Resolution & $1 \mathrm{~nm}$ \\
X Scanned & $500 \mu \mathrm{m}$ \\
Y Scanned & $500 \mu \mathrm{m}$ \\
Lens & $100 \mathrm{X}$ \\
Working Distance & $5 \mathrm{~mm}$ \\
Numerical Aperture & 0.9 \\
\hline
\end{tabular}



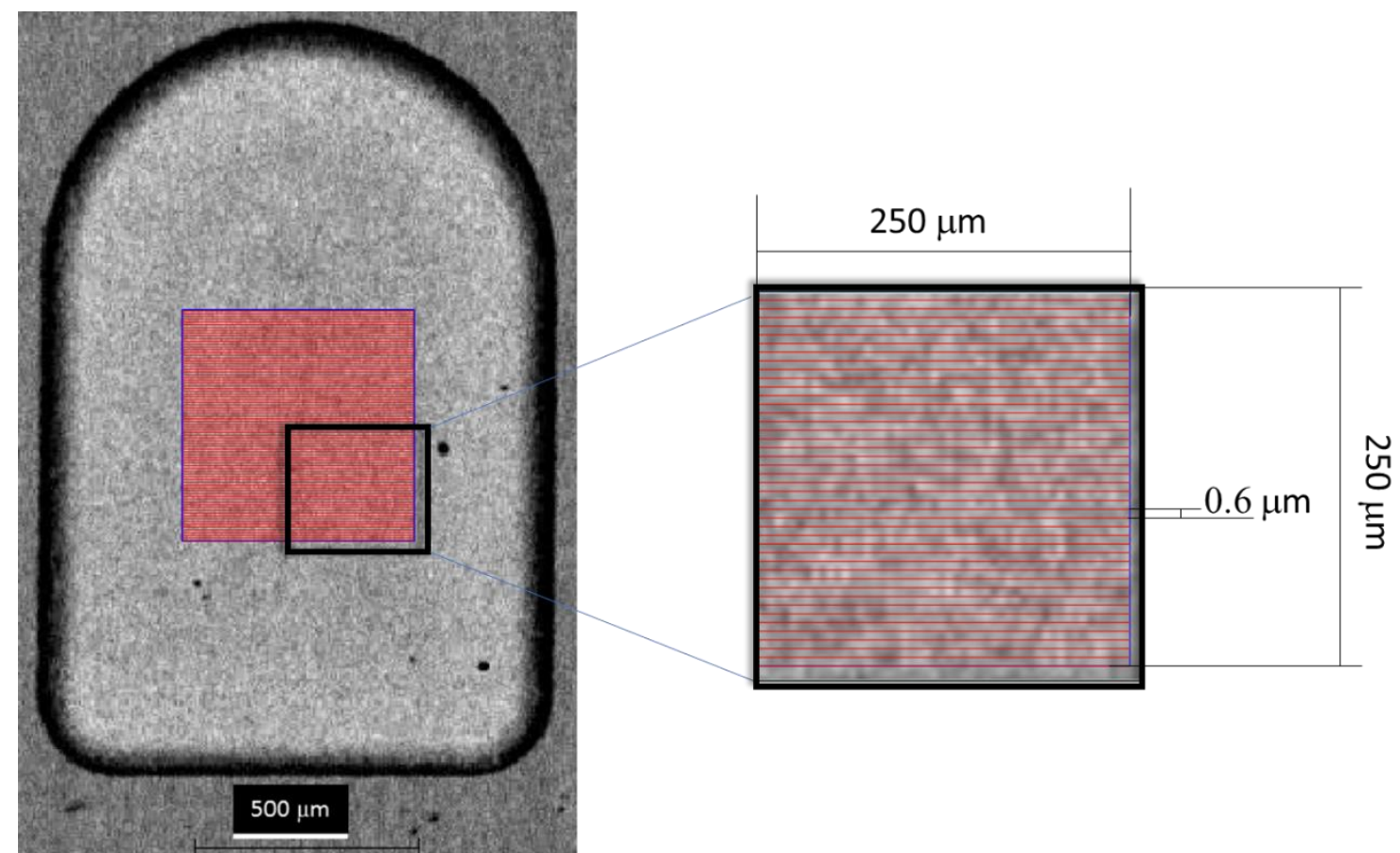

Fig. 2. Portion of pocket scanned.

\subsection{Surface roughness evaluation}

For the evaluation of surface geometry some amplitude parameters $\left(S_{\mathrm{a}}, \mathrm{S}_{\mathrm{sk}}, \mathrm{S}_{\mathrm{ku}}\right)$ are evaluated starting from the data collected by the laser probe and elaborated using the equations defined by the standard ISO 25178. This standard is concerned with the geometric irregularities of the surfaces defining surface texture and its constituents: roughness, waviness and lay.

First of all, average roughness $\left(\mathrm{S}_{\mathrm{a}}\right)$ is estimated. It expresses, as an absolute value, the difference in height of each point compared to the arithmetical mean of the surface. It is easy to measure and it allows to obtain a good description of height variations, but it does not give any information about the wavelength and it is no sensitive to small changes in profile. It is calculated as follows:

$$
S_{a}=\frac{1}{A} \iint_{A}|z(\mathrm{x}, \mathrm{y})-\mathrm{m}(\mathrm{x}, \mathrm{y})| d x d y
$$

where $\mathrm{z}(\mathrm{x}, \mathrm{y})$ indicates the ordinate values defined in area $(\mathrm{A})$ and $\mathrm{m}(\mathrm{x}, \mathrm{y})$ is calculated taking into account an interpolation surface with the following general equation:

$$
m(x, y)=a x^{2}+b x y+c y^{2}+d x+e y+f
$$


This interpolation surface is introduced to take into account the waviness of the sampled area. Its identification is carried out as follows.

The surface coefficients are grouped in matrix B:

$$
B=\left[\begin{array}{l}
a \\
b \\
c \\
d \\
e \\
f
\end{array}\right]
$$

And are calculated according to Eq.3:

$$
B=\left(X^{\prime} \cdot X\right)^{-1} \cdot X^{\prime} \cdot Y
$$

Where: $X=\left[\begin{array}{cccccc}1 & x_{0}^{2} & x_{0} y_{0} & y_{0}^{2} & x_{0} & y_{0} \\ \vdots & \vdots & \vdots & \vdots & \vdots & \vdots \\ 1 & x_{i}^{2} & x_{i} y_{i} & y_{i}^{2} & x_{i} & y_{i}\end{array}\right]$ and $Y=\left[\begin{array}{c}z_{0}(x, y) \\ \vdots \\ z_{i}(x, y)\end{array}\right]$

And where $\mathrm{x}_{\mathrm{j}}, \mathrm{y}_{\mathrm{j}}$ represent the coordinates of the $\mathrm{j}$-th point of the sampled surface having a height equal to $\mathrm{z}_{\mathrm{j}}$.

The root mean square roughness $\left(\mathrm{S}_{\mathrm{q}}\right)$ represents the standard deviation of the distribution of surface heights, so it is an important parameter to describe the surface roughness from a statistical point of view. The mathematical definition is reported in Eq. 4.

$$
S_{q}=\sqrt{\frac{1}{A} \iint_{A}(z(x, y)-m(x, y))^{2} d x d y}
$$

To distinguish between two profiles having the same $S_{a}$, two further amplitude parameters are considered: skewness $\left(\mathrm{S}_{\mathrm{sk}}\right)$ and kurtosis $\left(\mathrm{S}_{\mathrm{ku}}\right)$. These parameters give information about the statistical average properties.

The surface skewness $\left(S_{\text {sk }}\right)$ is the third central moment of the profile amplitude probability density function, measured over the assessment length (Eq. 5).

$$
S_{s k}=\frac{1}{S_{q}^{3}} \cdot \frac{1}{A} \iint_{A}(z(x, y)-m(x, y))^{3} d x d y
$$

It describes the asymmetry of the height distribution histogram. It is represented by the quotient of the mean cube value of the ordinate values and the cube of $S_{q}$ within a definition area (A). Fig. 3 clarify the meaning of this parameter. Symmetrical height distribution has zero skewness; in fact, the profile is characterized by as many peaks as valleys. Profile with peaks removed or deep 
scratches have negative skewness, while profiles with valleys filled in or high peaks have positive skewness.

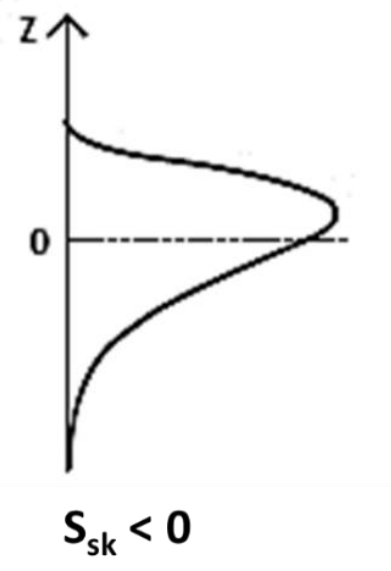

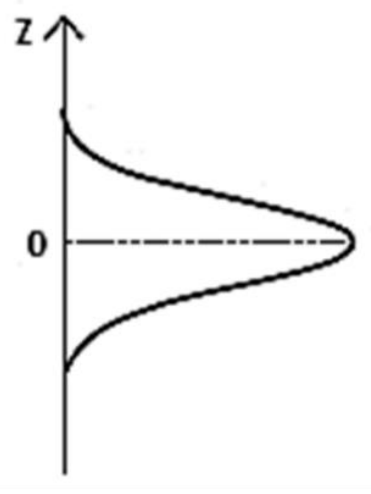

$\mathrm{S}_{\mathrm{sk}}=\mathbf{0}$

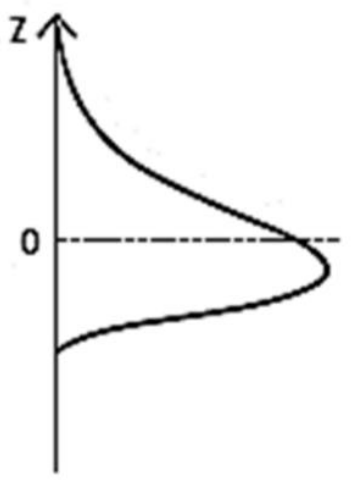

$\mathbf{S}_{\text {sk }}>0$

Fig. 3. Definition of skewness $\left(\mathrm{S}_{\mathrm{sk}}\right)$.

The surface Kurtosis $\left(\mathrm{S}_{\mathrm{ku}}\right)$ coefficient is the fourth central moment of profile amplitude probability density function, measured over the assessment length (Eq. 6).

$$
S_{k u}=\frac{1}{S_{q}^{4}} \frac{1}{A} \iint_{A}(z(x, y)-m(x, y))^{4} d x d y
$$

This parameter describes the sharpness of the probability density of the profile; it is the quotient of the mean quadratic value of the ordinate values and the fourth power of $S_{q}$ within a definition area (A). If $S_{\mathrm{ku}}<3$ the distribution curve is said to be platykurtoic and has relatively few high peaks and low valleys. On the contrary, if $S_{\mathrm{ku}}>3$, the distribution curve is said to be leptokurtoic and has relatively many high peaks and low valleys (Fig. 4). 


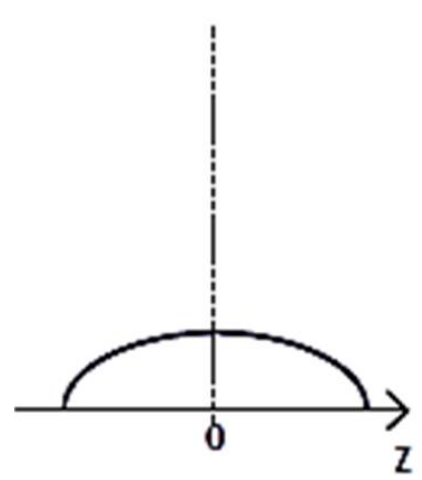

$\mathrm{S}_{\mathrm{ku}}<3$

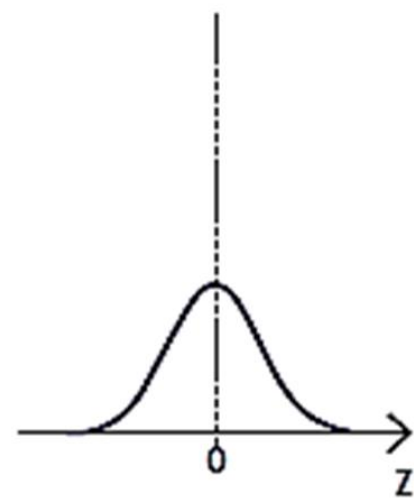

$\mathrm{S}_{\mathrm{ku}}=\mathbf{3}$

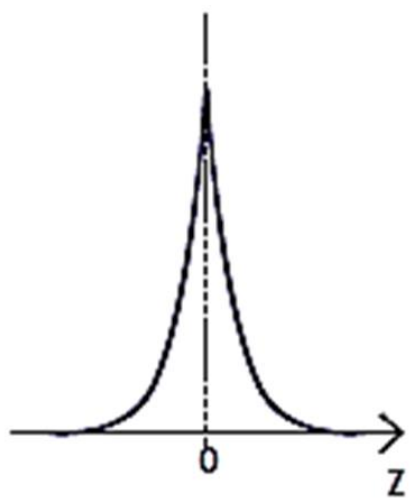

$\mathrm{S}_{\mathrm{ku}}>3$

Fig. 4. Definition of kurtosis $\left(\mathrm{S}_{\mathrm{ku}}\right)$.

All these calculations were carried out using a Matlab script developed by the authors.

\section{Results and discussion}

The data collected by the autofocus laser probe were firstly elaborated to get the images of the reconstructed surfaces in STL format. A graphical comparison between the surfaces obtained using the different combination of process parameters on AISI 316L is reported in Fig. 5 (a). In general, for finishing and fine-finishing processes the craters are shallow and the surface irregularities are smooth. Whereas for pre-rough and rough machining, the craters are deeper and surface irregularities are most apparent. Fig. 5 (b) shows the surface aspect obtained on $\mathrm{ZrC}+10 \mathrm{MoSi}_{2}$. The comparison between Fig. 5 (a) and (b) clearly shows the different aspects of the surfaces for the two materials; in fact, the first one is characterized by well-defined craters with dimensions related to the machining type. The craters are less evident on the ceramic surfaces; the same consideration can be done for their dimensions. 

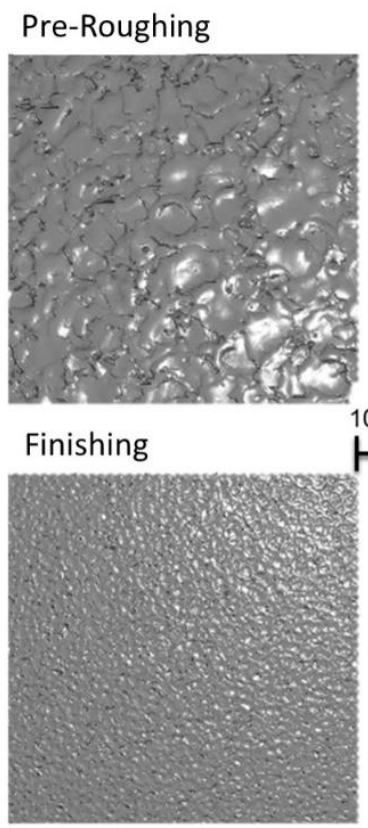

E105

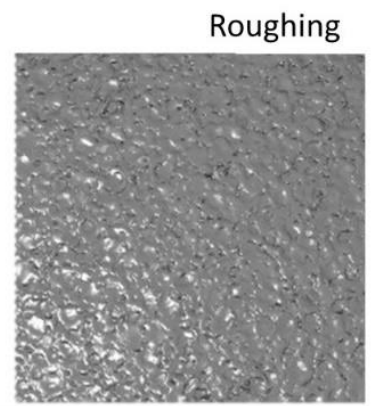

$100 \mu \mathrm{m}$
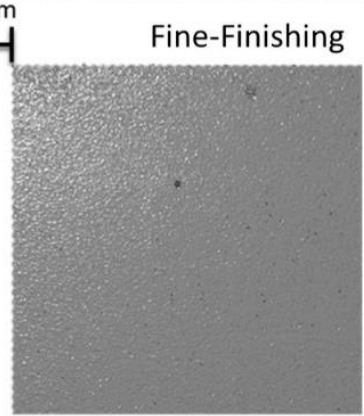

E13

(a)
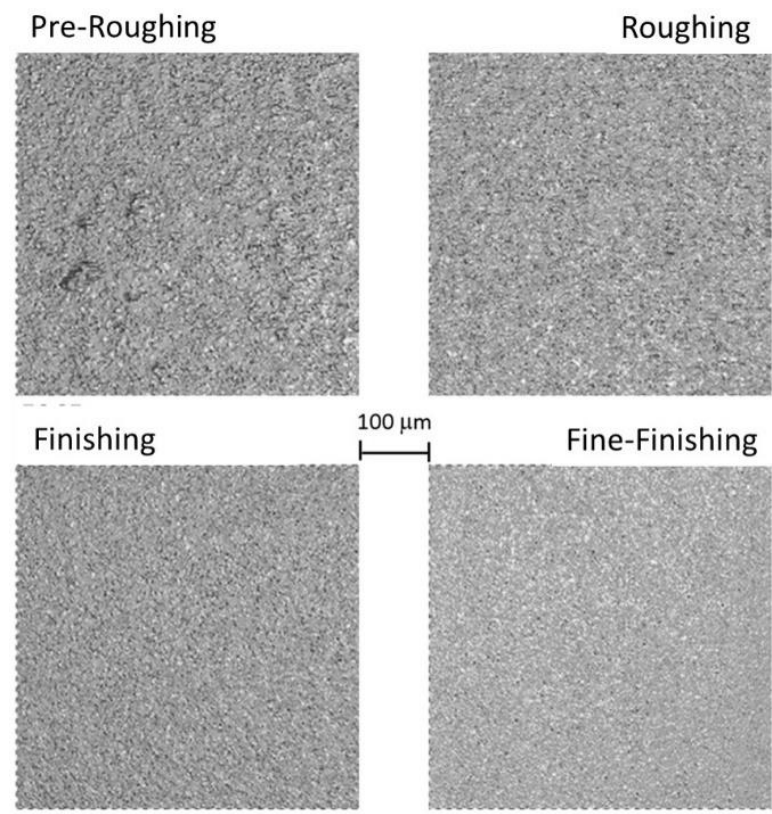

$100 \mu \mathrm{m}$

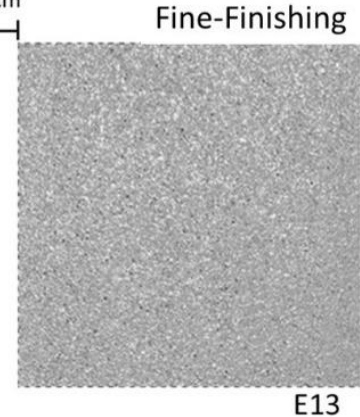

(b)

Fig. 5. Graphical comparison of reconstructed surfaces for stainless steel (a) and ceramic (b).

Fig. 6 and Fig. 7 show the deviation of meshes with respect to a reference plane for AISI 316L and for the ceramic material. The histograms in the figures represent the distribution of the $\mathrm{z}(\mathrm{x}, \mathrm{y})$. The colours scale underlines the distance of each point of the surface from the reference plane. Several working witnesses can be observed on the ceramic surface. The analysis of the deviations shows that the electrode trace becomes evident, on both materials, for the fine-finishing operation.
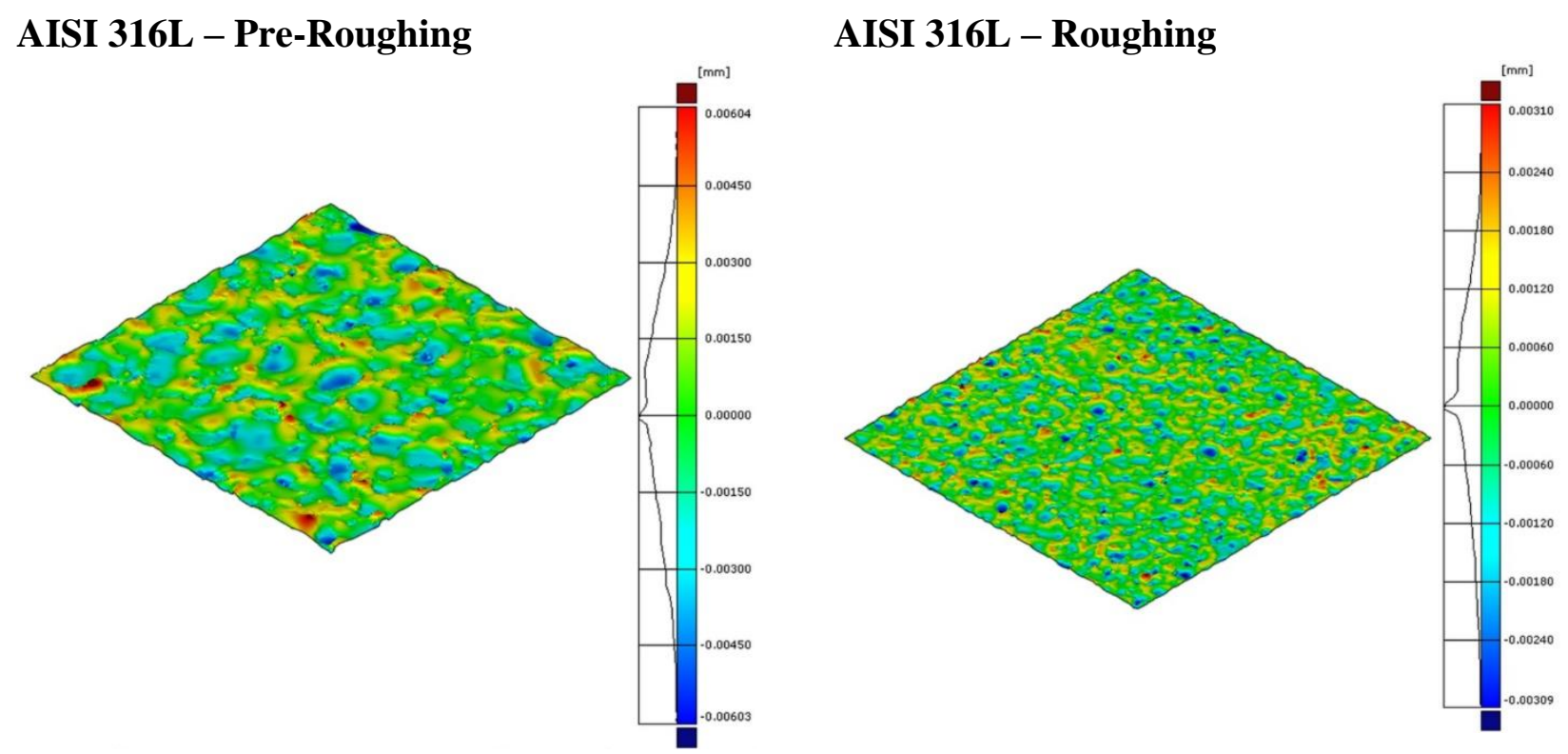

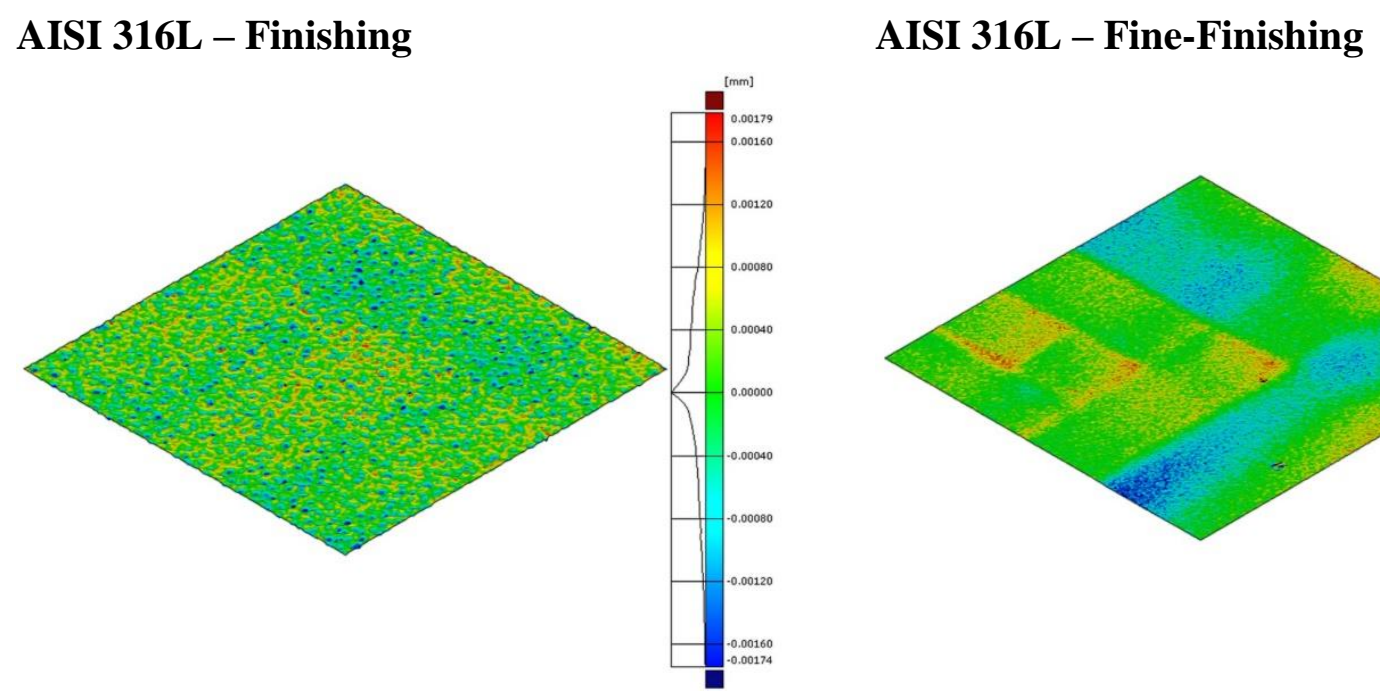

Fig. 6. Deviation from the geometry of micro-pockets performed on AISI 316L (GOM Inspect).

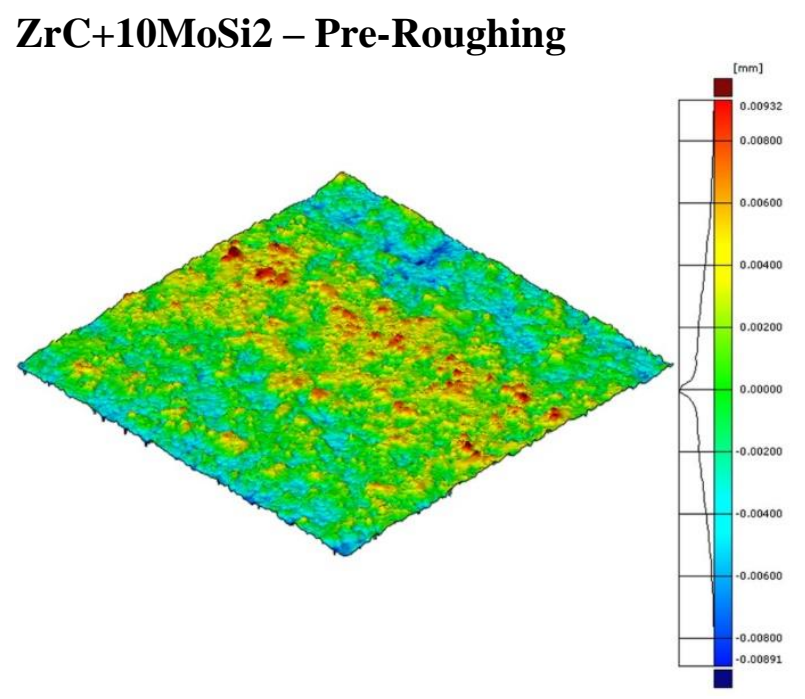

ZrC+10MoSi2 - Finishing

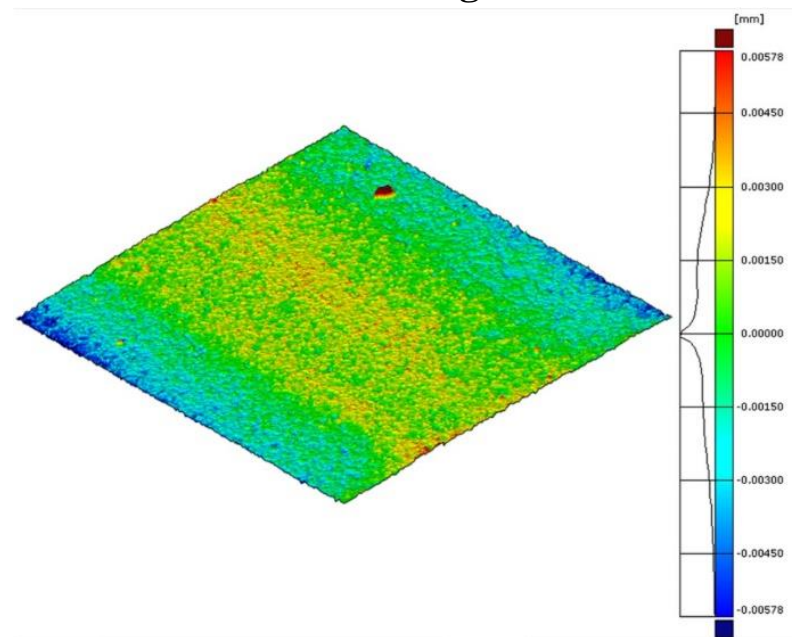

\section{ZrC+10MoSi2 - Roughing}

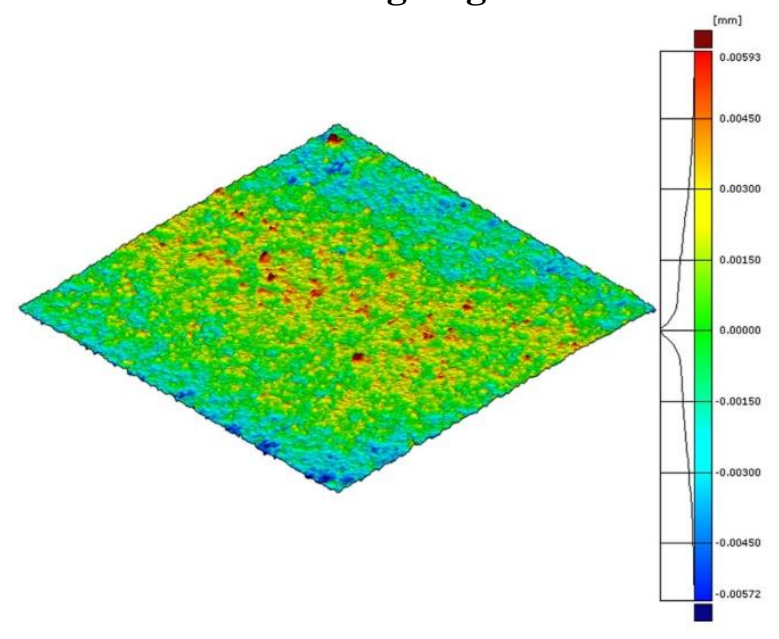

ZrC+10MoSi2 - Fine-Finishing

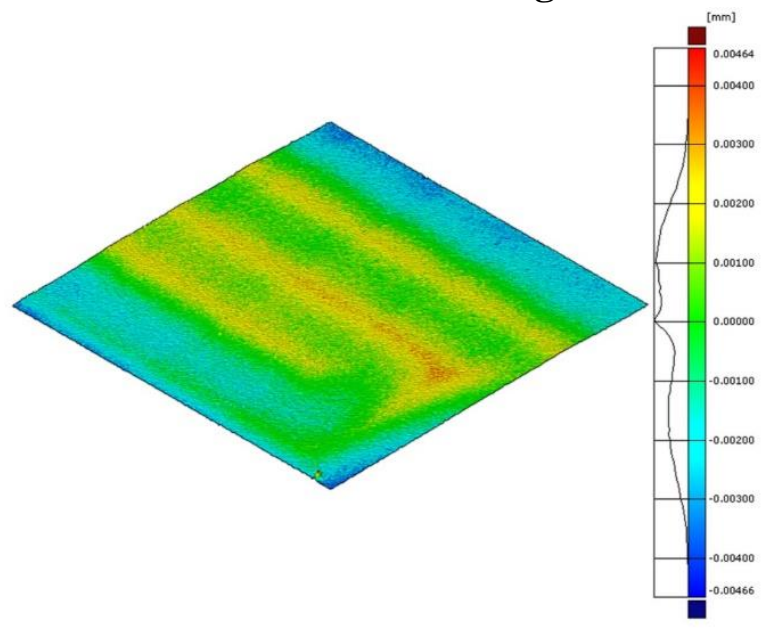

Fig. 7. Deviation from the geometry of micro-pockets performed on $\mathrm{ZrC}+\mathrm{MoSi} 2$ (GOM Inspect). 
Fig. 8 shows the trend of the $S_{a}$ as function of the process type. The trends are similar for the two materials, even if the values obtained for steel are always lower than those obtained for ceramic. This effect can be related to the different material structures and, in particular, to the porosity of the sintered ceramic. These results agree with literature review; in fact, surface roughness improve when voltage and pulse on time decrease, while the peak current and the frequency increase. This means that to obtain a fine-finishing surface the electrical discharge, developed in the gap during the machining, must be short pulses.

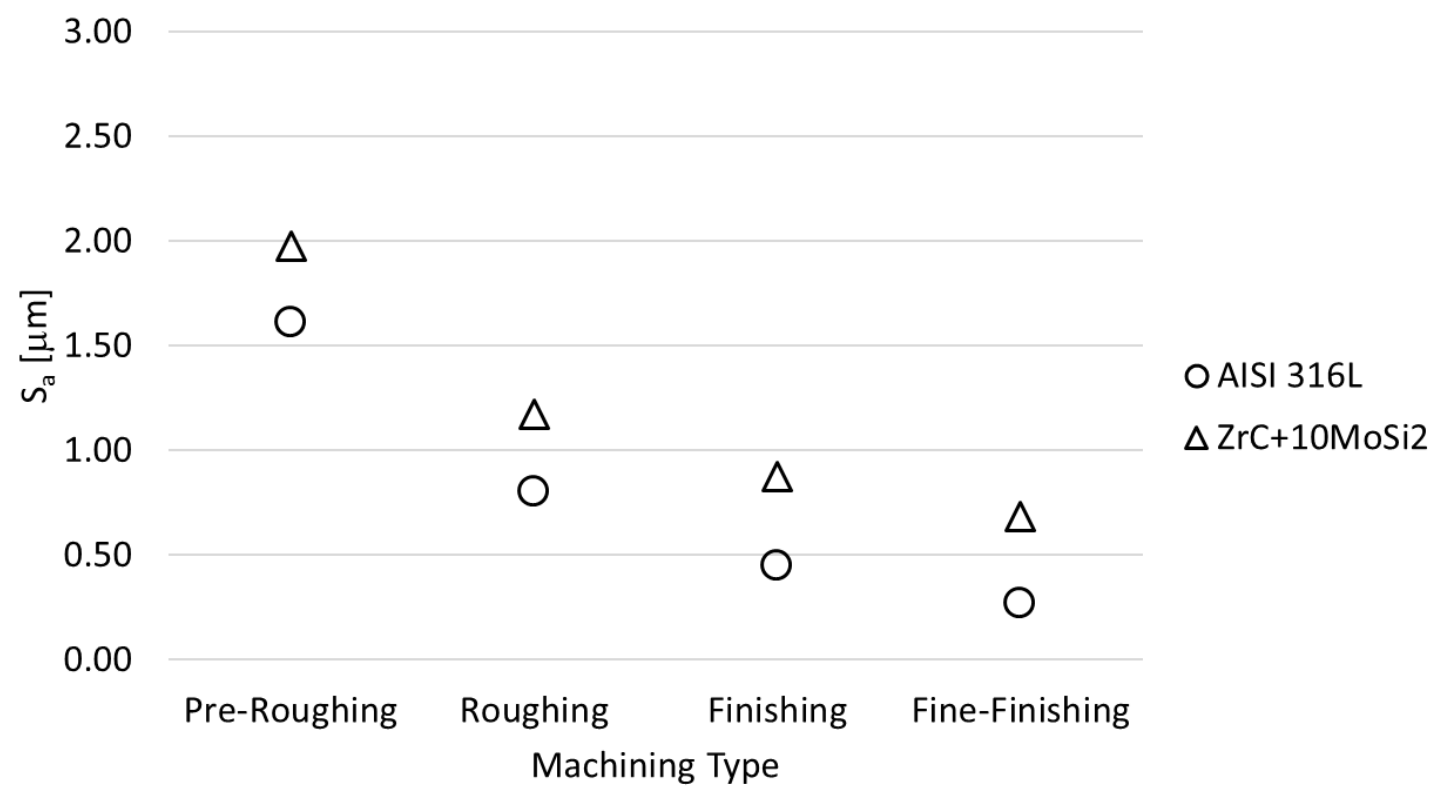

Fig. 8. Roughness for two materials as a function of machining type.

Fig. 9 and Fig. 10 show the calculated values of root mean square $\left(S_{\mathrm{q}}\right)$, kurtosis $\left(\mathrm{S}_{\mathrm{ku}}\right)$ and skewness $\left(\mathrm{S}_{\mathrm{sk}}\right)$ for the machined surfaces. The skewness characterizes the statistical distribution in terms of asymmetry. If the value is close to 0 , the distribution is symmetric and it is well represented by a Gaussian distribution. In particular, the $S_{\text {sk }}$ for stainless steel results negative for all the machining approaches and this means that the bulk of the material of the sample is above the mean line. In this case the material of machined surface is mainly distributed into valleys, such as it is possible to see in the 3D reconstruction previously reported. On the contrary, for the machining performed on ceramic material, the bulk of the material is below the mean line (Fig. 11). 
In all cases, the kurtosis results greater than 3 (Fig. 12): this means that the machined surfaces are characterized by relatively few high peaks and valleys; in fact, the frequency of distribution are higher for the central values. Similar trends can be observed for two materials as function of the machining type. In particular, in both cases there is a reduction in the kurtosis for the fine-finishing operations. It is important to remark that $S_{\mathrm{ku}}$ values near to 3 are typical of a near-to-Gaussian distribution. Another important parameter for the data analysis is $S_{\mathrm{q}}$ that represents the standard deviation, so giving a measure of width of the distribution (Fig. 9 and Fig. 10).

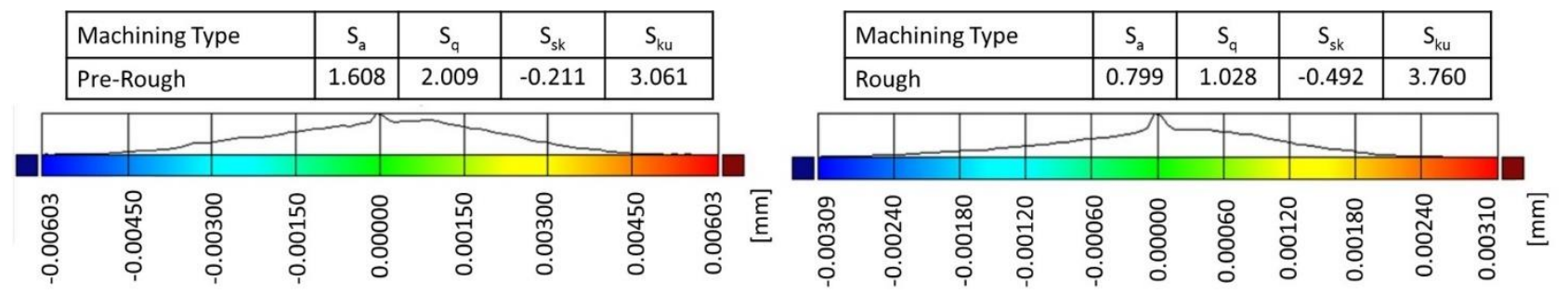

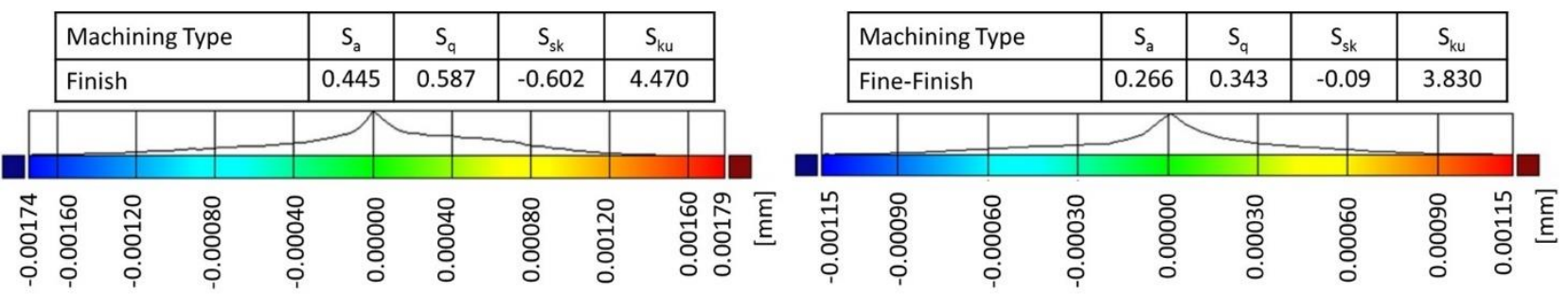

Fig. 9. Histogram and roughness parameters obtained on AISI 316L (GOM Inspect).

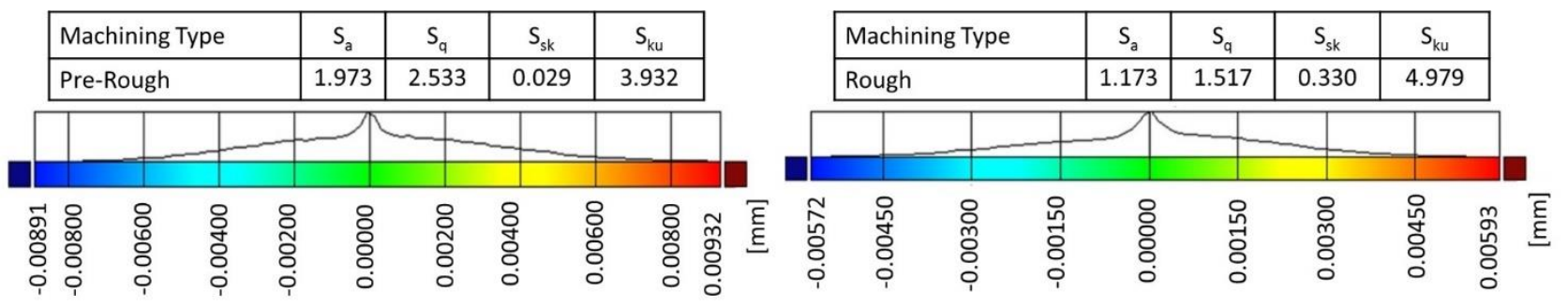

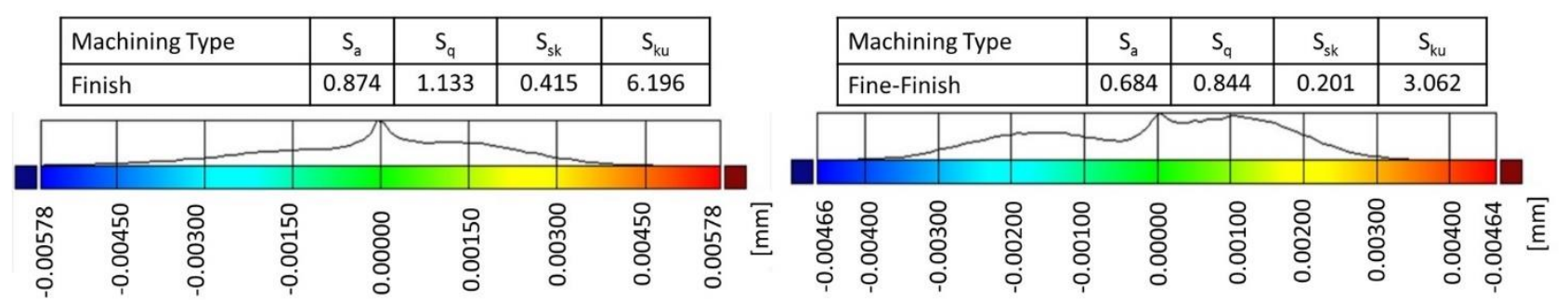

Fig. 10. Histogram and roughness parameters obtained on $\mathrm{ZrC}+10 \mathrm{MoSi}_{2}(\mathrm{GOM}$ Inspect). 


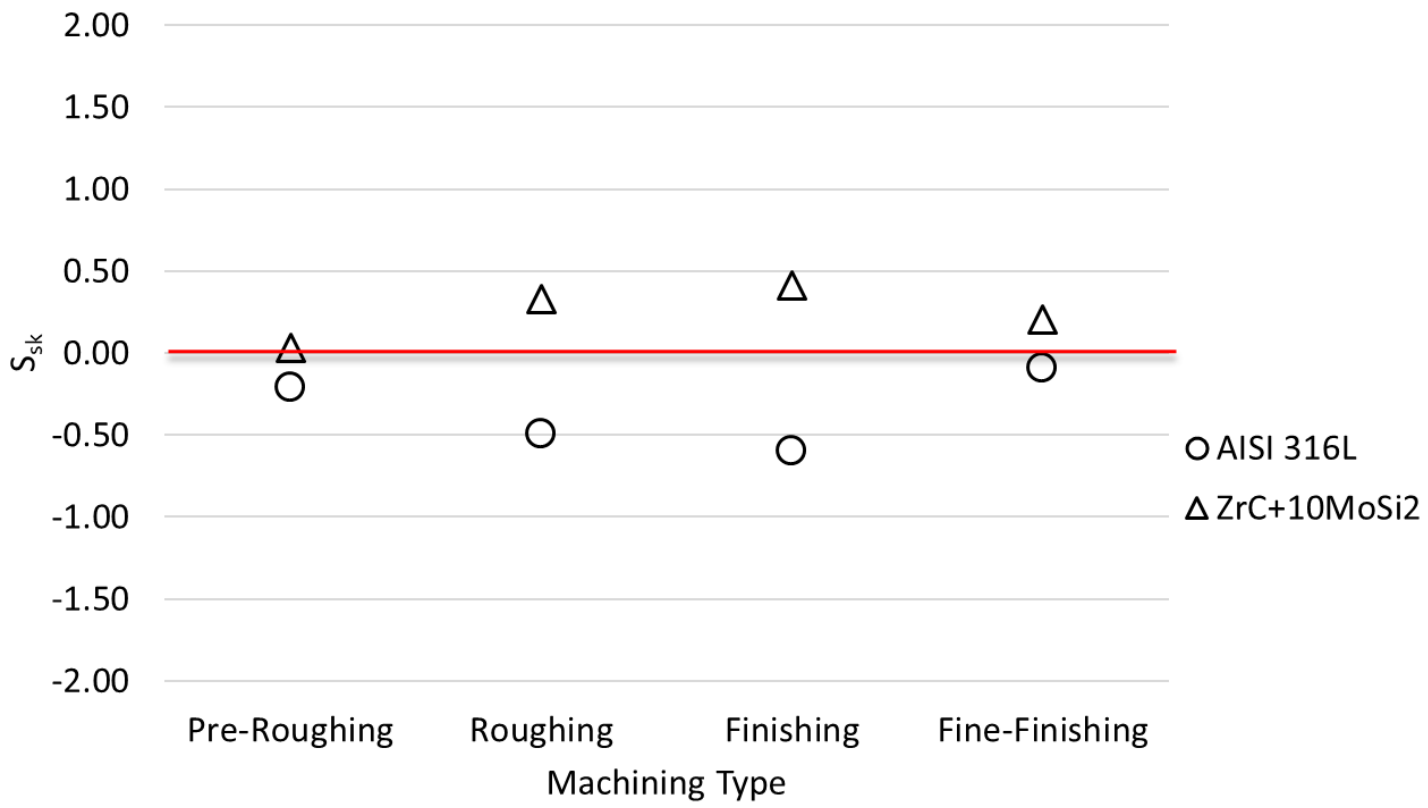

Fig. 11. Skewness distribution for two materials as a function of machining type.

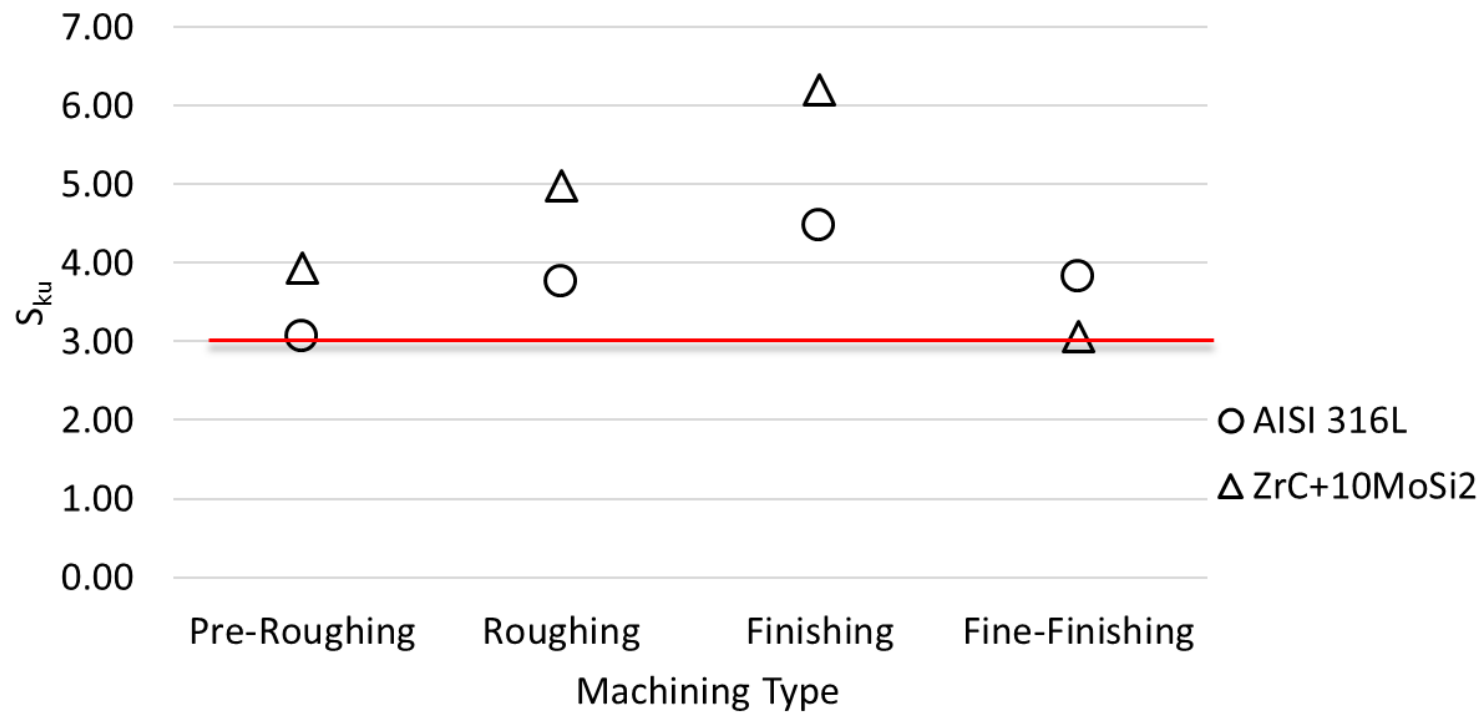

Fig. 12. Kurtosis distribution for two materials as a function of machining type.

Even though similar trends can be observed for ceramic and steel, the differences in skewness and kurtosis values denotate dissimilar characteristics between the two materials. In particular, since skewness value for AISI 316L is negative, most of the material is above the mean line; on the contrary, most of the ceramic material is below the mean line. This effect can be explained by the 
different material structures and by the presence of voids (caused by the sintering process) for the ceramic material.

\section{Conclusions}

In the present paper, differences in surface characteristics when working stainless steel and ceramic material are outlined as function of the machining type. These differences are not limited to the calculus of $S_{a}$ but also consider other parameters, as suggested by ISO 25178 . The results of this investigation are important and must be carefully considered in relation to the final application of the produced part.

Considering further parameters other than $S_{a}$ allows more complete analysis of the surface quality giving a more accurate information of peaks and valleys shape and distribution with respect to the mean line.

The proposed method starts from the optical sampling of the surface by means of an autofocus laser probe equipment. The sampled points cloud is then tasselled for reconstructing the actual surface and used to map the deviation of the mesh with respect to the interpolating surface. This latter gives the opportunity of filtering the data to consider the waviness effects.

The proposed method was applied to two materials different in terms of structure, mechanical and physical properties and, in particular, to AISI 316L stainless steel and ultra-high temperature ceramic $\mathrm{ZrC}+10 \mathrm{MoSi}_{2}$.

\section{References}

[1] Qin Y, Brockett A, Ma Y, Razali A, Zhao J, Harrison C, Pan W, Dai X, Loziak D (2010) Micro-manufacturing: research, technology outcomes and development issues. Int J Adv Mnuf Techno 47:821-837. DOI: 10.1007\%2Fs00170-009-2411-2

[2] Dimov S, Pham DT, Ivanov A, Popov K (2003) Tool-path generation system for microelectro discharge machining milling. J Eng Manuf 217(B):1633-1637. DOI: 10.1243/095440503771910014 
[3] Karthikeyan G, ramkumar J, Dhamodaran S, Aravindan S (2010) Micro electric discharge milling process performance: An experimental investigation. Int J Mach Tool Manuf 50:718-727. DOI: 10.1016/j.ijmachtools.2010.04.07

[4] Kurnia W, Tan PC, Yeo SH, Tan QP (2009) Surface roughness model for micro electrical discharge machining. Proc Inst Mech Eng 223(3):279-287. DOI:

\subsection{3/09544054JEM1188}

[5] Lin YC, Yan BH, Huang FY (2001) Surface Improvement Using a Combination of Electrical Discharge Machining with Ball Burnish Machining Based on the Taguchi Method. Int J Adv Man Tech 18:673-682. DOI: 10.1007\%2Fs001700170028

[6] Keskin Y, Selçul Halksci H, Kizil M (2006) An experimental study for determination of the effects of machining parameters on surface roughness in electrical discharge machining (EDM). Int J Adv Manuf Technol 28:1118-1121. DOI: 10.1007/s00170-004-2478-8.

[7] Ramasawmy H, Blunt L (2004) Effect of EDM process parameters on 3D surface topography. J Mater Process Technol 148:155-164. DOI: 10.1016/S0924-0136(03)00652-6

[8] Whitehouse DJ (2003) Handbook of surface and nano metrology. Institute of Physics, IOP publishing, London.

[9] Bhushan B (2001) Surface roughness analysis and measurement techniques. Chemical Rubber Company (CRC) Press LLC.

[10] Whitehouse DJ (1997) Surface metrology. Meas Sci Technol 8:955-972.

[11] Al-Kindia GA, Shirinzadeh B (2007) An evaluation of surface roughness parameters measurement using vision-based data. Int J Mach Tool Manuf 47:697-708. DOI: 10.1016/j.ijmachtools.2006.04.13

[12] Kuang-Chyi L, Shinn-Jang H, Shinn-Ying H (2005) Accurate estimation of surface roughness from texture features of the surface image using an adaptive neuro-fuzzy inference system. Precision Engineering 29:95-100. DOI: doi.org/10.1016/j.precisioneng.2004.05.002

[13] Keskin Y, Selçuk Halkaci H, Kizil M (2006) An experimental study for determination of the effects of machining parameters on surface roughness in electrical discharge machining (EDM). Int J Adv MAnuf Techno 28:1118-1121. DOI: article/10.1007\%2Fs00170-004-24788

[14] ISO 25178-1: 2016 Geometrical product specifications (GPS) -- Surface texture: Areal Indication of surface texture.

[15] ISO 25178-2: 2012 Geometrical product specifications (GPS) -- Surface texture: Areal Terms, definitions and surface texture parameters 
[16] Kiran MB, Ramakrishna H, Kuppahalli P (2011) A study on the evolution of surface roughness characterization. Manufacturing Technology Today, $1^{\circ}$ National Conference on Advanceds in Metrology CMTI, 11-16.

[17] Abou El-Atta UB (1991) Surface roughness assessment in three-dimensional machined surfaces for some manufacturing operations, M.Sc. Thesis, Industrial Production Engineering Department, University of Mansoura, Egypt.

[18] Teague EC, Scire FE, Baker SM, Jensen SW (1982) 3-Dimensional stylus profilometry. Wear 83(1):1-12. DOI: 10.1016/0043-1648(82)90335-0

[19] Gadelmawla ES, Koura MM, Maksoud TMA, Elewa IM, Soliman HH (2002) Roughness paramters. J Mater Parocess Techno 123:133-145.

[20] Hyde JM, Cadet L, Montgomery J, Brown CA (2014). Multi-scale areal topographic analysis of surfaces created by micro-EDM and functional correlations with discharge energy. Surf Topogr Metrol Prop 2(4). DOI:10.1088/2051-672X/2/4/045001.

[21] Zhang XL, Wang ZX (2017). Experimental Research of Effects of Electric Parameters on the Machining Speed and Surface Quality in EDM. Mater Sci Forum 893:257-261. DOI:10.4028/www.scientific.net/MSF.893.257.

[22] Feng W, Chu X, Hong Y, Zhang L (2017). Studies on the surface of high-performance alloys machined by micro-EDM. Mater Manuf Process.

DOI:10.1080/10426914.2017.1364758. 